\title{
Status of Rural Health Care and the Hidden Disparity: A Study of Birbhum District, West Bengal, India.
}

\author{
${ }^{1}$ Mr. Subhajit Ghatak, ${ }^{2} \mathrm{Mr}$. Partha Pratim Das \\ ${ }^{1}$ Assistant Teacher (Geography), Bijoypur Palsona High School (H.S.), Burdwan, W.B., India. \\ ${ }^{2}$ Assistant Teacher (Geography), Kapasdanga K.H. High School, P.O.-Bharkata, Birbhum, W.B., India.
}

\begin{abstract}
Health is the key concept to human happiness. It has a pronounced impact in both social and economic development of the society. So, for the all-round development process basic health care facility is the essential criteria. Health care system in the district of Birbhum of West Bengal is very far from the level of satisfaction, especially from the infrastructural point of view. Lacking of this facility leads to inconsistency in the development of basic health care system as well as in overall development of the society. Discrepancies existed both in spatial and temporal scale. The forgoing analysis is an attempt to glean out the level of disparity and role of different factors in such disparity in health care system in the district of Birbhum, West Bengal.

Key words: Bed - Population Ratio,Dimension Index, Health Index, Doctors - Population Ratio, Medical institution - Population Ratio, Family Welfare Society, Universal Health Coverage.
\end{abstract}

\section{Introduction:}

Economic structure is essentially the backbone of overall development process for a nation, especially, on the present day circumstances when global financial crisis severely affects the world economic structure. Hence, for the proper development practice always requires an innovative, ever growing economy which in turns requires greater innovations in the field of human capital. Better quality of human capital always fortify better economic as well as social development process. But the question is what does better human capital indicate? It includes healthy, educated and skillful humans. Education and experience are the vital factor in this regards, but the role of better health is the most important. More healthy populations mean greater inputs the process of resource generation and economic growth. Analysis of the effect of health on economic development clearly shows a strong positive correlation. A long term study for England by Robert Fogel, a Nobel laureate in economics, also demonstrates this. According to Jocelyn Finley (2007), health influences economic growth via education incentives ${ }^{1}$. Bloom et al. (2004), Webber (2002), Knowles and Owen (1997) focuses on the labour productivity effects of health on economic growth where an improvement in health leads to an increase in per capita income directly as each individual is able to produce more per unit of labour input (Jocelyn Finley, 2007). So, without any doubt, health makes an important contribution to human development process and because of this, health was identified as a component of human development in the Human Development Report 1990 (UNDP 1991).Even assessing the situation, World Bank has shifted from an emphasis on promoting economic growth (i.e. commission on International Development, 1969) to include a focus on health, education and social exclusion (World Development Report, 2001).

But in general, how to define health? According to W.H.O., "it is a complete state of physical, mental and social wellbeing including the absence of illness". It reflects through a better life expectancy, low mortality and morbidity rate with an intense health care facility. Several attempts have been made throughout the world for the development of health care facilities in search of healthy prosperous life and India is not an exception. Along with various development processes, health standards in India have improved considerably since independence. With the concerted efforts of the government and other public-private agencies, some of the health indicators in India experienced impressive growth. Longevity has more than double since independence, Infant Mortality Rate has fallen, malaria has been contained, small pox and guinea worm have been completely eradicated and leprosy and polio are nearing elimination (Kurukshetra, February 2010, vol-58, p-2). Despite these achievements, the health care facilities provided by India to her people are not adequate. Even it is amongst the lowest comparing to other countries. Even the regional disparity regarding the medical facilities within India is remarkable. Some of her states enjoyed a progressive health care facility, whereas others are heavily over burdened by ill-fed, ill-sheltered unhealthy population.

Present study is an attempt to unfold the block level disparity of health care facility in the district of Birbhum, West Bengal which comprises of nineteen blocks enriched in agricultural economy. 
Status Of Rural Health Care And The Hidden Disparity: A Study Of Birbhum District, West Bengal,

Objectives:

The main objective of this research are-

$>$ To find out the spatial pattern of disparity regarding the health care facility through the calculation of Health Index in different blocks of Birbhum district and in the implementation of Universal Health Coverage; and

$>$ To prescribe some recommendations for mitigating such disparity.

Database and Methodology:

The study is based on the block level data from the District Statistical Handbook of Birbhum (20072008) and thus secondary in nature.

Considering the case of methodology, it is purely quantitative in nature. Quantification is mainly adopted in the formulation of Health Index to analyze the spatial variation of health care facilities in the area using four health related parameters. The parameters are:

1. Medical institution-People Ratio: Number of medical institution (including PHC, rural health centers, nursing homes etc.) per thousand of population (MPR).

2. Bed-Population Ratio: Number of hospital beds per thousand of population (BPR).

3. Doctor-Population Ratio: Number of hospital doctors per thousand of population (DPR).

4. Sub centers-Population Ratio: Number of Family Welfare Centers and Sub-centers per thousand of population (SPR).

The Health Index is the simple arithmetic average of these parameters

$$
H I=1 / 4(M P R+B P R+D P R+S P R)
$$

To work out the Dimension Index of individual parameters the following formula has been used:

Dimension Index = (Actual Value - Minimum Value $) /($ Maximum Value - Minimum Value $)$

(Human Development Report, 2002)

\section{Study Area:}

The study area includes all nineteen blocks of Birbhum district (excluding the municipal areas), situated in the western part of West Bengal and surrounded by Burdwan district in the south, Murshidabad in the north east and by the state of Jharkhand in the west. It comprises an area of $4545 \mathrm{sq} . \mathrm{k} . \mathrm{m}$. having a population of 3015422 (Census 2001) with a population density of 663 person per sq. k.m. The geographical coordinates of the district are $23^{\circ} 32^{\prime} 30^{\prime \prime} \mathrm{N}$ to $24^{\circ} 35^{\prime} 00^{\prime \prime} \mathrm{N}$ and $87^{\circ} 05^{\prime} 25^{\prime \prime} \mathrm{E}$ to $88^{\circ} 01^{\prime} 40^{\prime \prime} \mathrm{E}$. The district has a history of distinct culture influenced by the great poet Rabindranath Tagore.

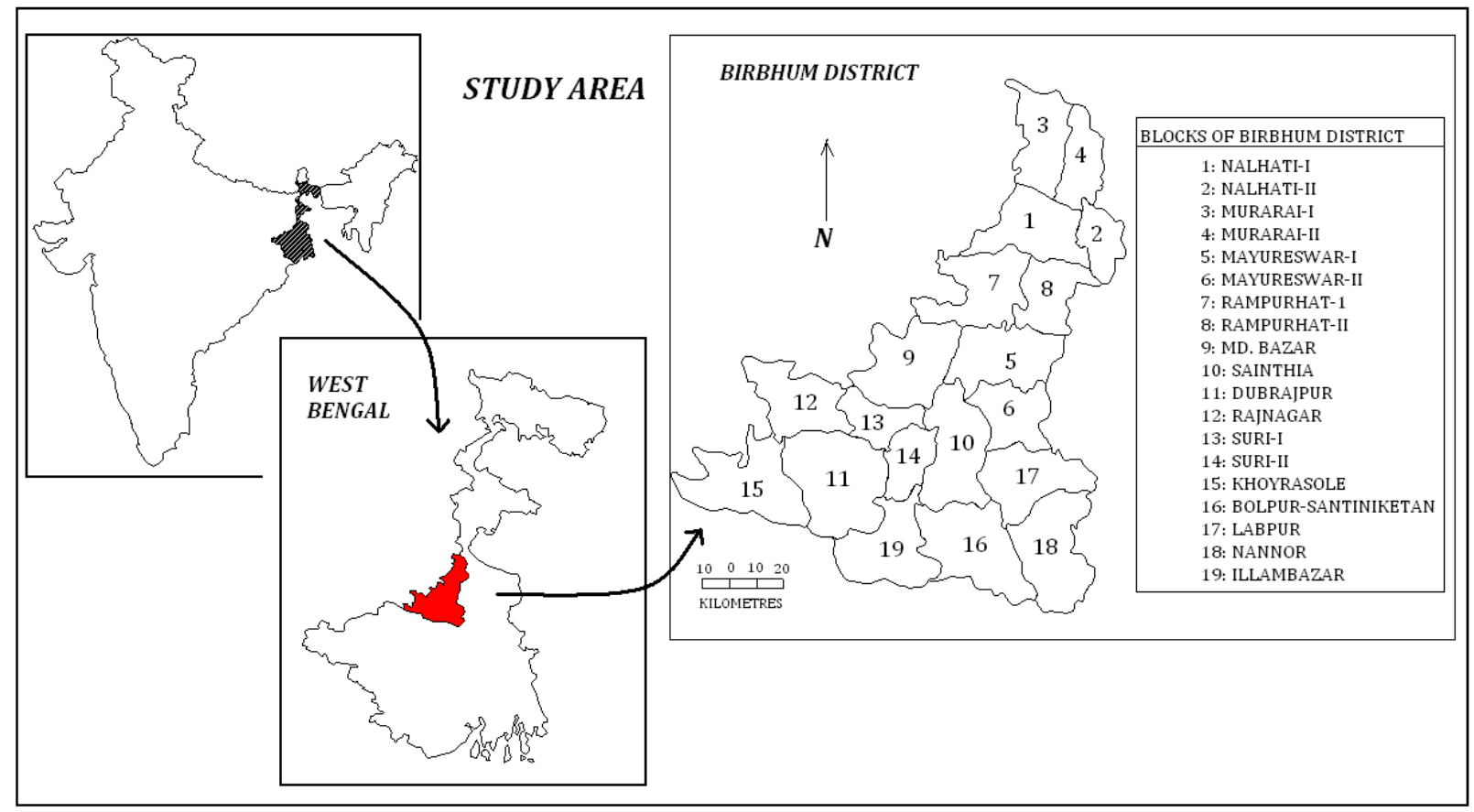

FIGURE-1: THE STUDY AREA

Elementary health care system in India - a synoptic view:

It is the period of Independence after which people of India witness a huge takeoff in the overall development process and the rural health care facility is not an exception in this regard. With the 
Status Of Rural Health Care And The Hidden Disparity: A Study Of Birbhum District, West Bengal,

implementation of several plans and policies regarding the health care facility, the standard of living in India has been increased remarkably. Decreasing rate of Infant Mortality, increasing Life Expectancy at Birth and eradication of some pandemic diseases are some example of such development. But still India has some valid reasons to cry for rural health care facility. According to the report of W.H.O.-

$\checkmark$ India accounts for $21 \%$ of the Worlds global burden of diseases.

$\checkmark$ India is losing more than 6\% of its GDP annually due to premature deaths and preventable illness.

$\checkmark 42 \%$ of Indian children below the age of three are malnourished, which is greater than the Sub-Saharan Africa (28\%).

$\checkmark$ Approximately 1.72 million children in India die each year before turning one.

$\checkmark$ India is ranked $3^{\text {rd }}$ among the countries with the most HIV-infected population.

So, the above statement clearly reflects the degree of adequacy of Indian health care system which is very far from the expected level. More than that, intra-regional disparity in health care infrastructure has also become a major constraint in the process of equalized development. But for the past thirty years or more, Government of India along with different private institutions has made remarkable efforts in the field of health to mitigate such disparities. The list of initiatives includes the adoption of National Health Policy 1983, National Nutrition Policy 1992, Simple Health Insurance Scheme for poor in 2003, National Rural Health Mission in recent times etc. although those are not sufficient enough to solve the problem.

\section{Development of health care facility in Birbhum district:}

Birbhum is one of the prosperous districts of West Bengal regarding the agricultural practice and also well known for her distinct Tagorian culture, especially in the Bolpur -Santiniketan region. But from the point of view of health care facility the district is very far from the level of excellence. Every type of health related infrastructure requires a continuous attention for further development. To measure the health care facility in the mentioned district four infrastructure related parameters are taken into consideration from both spatial and temporal perspective.

Spatial variation in health care facility in Birbhum:

Every action and reaction on the earth surface is bounded by the spatio-temporal framework. So without the space dimension every phenomenon is incomplete within itself. For analyzing the spatiality of health care in the mentioned district following infrastructural parameters are included in the study:

Medical institution-population ratio is the expression of number of medical institute (includes Primary Health Centers, Block Primary Health Centers, Government Hospitals, Private Nursing Homes etc.) per thousand of population in different blocks of the district. This is perhaps the most important indicator in relation to the medical facility of a particular region. Increasing number of health centers always increases the probability of fast remedy from health related problems. But only a quantitative assessment such as the number of medical institution is not enough for the desired result, rather a quality assessment in terms of properly equipped medical centers (i.e. health related infrastructure) for better treatment facility is the most important.

In case of Birbhum district, significant block level disparities exist in terms of Medical institutionpopulation ratio. Some of the blocks such as Rampurhat-I (Dimension Index $=0.68$ ), Suri-I (0.86), Md. Bazar (0.65), Rajnagar (0.65) etc enjoys better health care facility in terms of medical institutions. Bolpur-Santiniketan block (1.00) is the most developed in this regard. On the other hand, Murarai-I (0.00), Mayureswar-I (0.05), Nalhati- I \& II (0.14 and 0.24), Nannor (0.19), Rampurhat-II (0.16), Illambazar and Murarai-II (both 0.24) have poor medical facility in terms of medical centers. Some of them such as Sainthia (0.41), Dubrajpur (0.51) etc are situated in between those extremes (Table-I).

Hospital bed-population ratio reflects the number of hospital beds per thousand of population of each block. It is also an important health related indicator that ensures indoor clinical facility at the time of emergency. Considering the case of Birbhum district regarding the bed-population ratio, only three blocks namely Dubrajpur (Dimension Index $=1.00)$, Rampurhat-I (0.97) and Bolpur-Santiniketan (0.64) stands in higher footing. Other than these three blocks, the condition is extremely poor (Dimension Index ranging from 0 to 0.3 ) mainly due to the lack of proper governmental initiatives (Table-I).

Doctor-population ratio illustrates the quantitative assessment of dependency of population on the hospital doctors. Doctors are the cornerstone of the health care system in any region because every type of medical infrastructure is totally futile in the absence of doctors. Increasing number of doctors increases the probability of getting cured. The condition of Birbhum district in this regard is as usual not satisfactory. Except the Rampurhat-I (1.00) and Bolpur-Santiniketan (0.69) block the overall scenario is very worrisome (Dimension Index = less than 0.3). Surprisingly the Dubrajpur block which has a good bed-population ratio, is not able to provide a handy numbers of doctors for the proper treatment of patients occupying those hospitals' bed. 


\begin{tabular}{|c|c|c|c|c|c|c|c|c|c|c|}
\hline \multicolumn{11}{|c|}{ CALCULATION OF HEALTH INDEX } \\
\hline $\begin{array}{l}\text { SL. } \\
\text { NO. }\end{array}$ & BLOCKS & $\begin{array}{c}\text { NO. OF } \\
\text { MEDICAL } \\
\text { INSTITUTI } \\
\text { ON PER } \\
\text { THOUSAN } \\
\text { D } \\
\text { POPULATI } \\
\text { ON }\end{array}$ & $\begin{array}{c}\text { DIM } \\
\text { ENSI } \\
\text { ON } \\
\text { INDE } \\
\mathbf{X}\end{array}$ & $\begin{array}{c}\text { NO. OF } \\
\text { BEDS } \\
\text { PER } \\
\text { THOUS } \\
\text { AND } \\
\text { POPULA } \\
\text { TION }\end{array}$ & $\begin{array}{c}\text { DIM } \\
\text { ENSI } \\
\text { ON } \\
\text { INDE } \\
\mathbf{X}\end{array}$ & $\begin{array}{l}\text { NO. OF } \\
\text { DOCTO } \\
\text { RS PER } \\
\text { THOUS } \\
\text { AND } \\
\text { POPULA } \\
\text { TION }\end{array}$ & $\begin{array}{c}\text { DIME } \\
\text { NSIO } \\
\mathbf{N} \\
\text { INDE } \\
\mathbf{X}\end{array}$ & $\begin{array}{c}\text { NO. OF } \\
\text { FWC AND } \\
\text { SUB } \\
\text { CENTRES } \\
\text { PER } \\
\text { THOUSAND } \\
\text { OF } \\
\text { POPULATI } \\
\text { ON }\end{array}$ & $\begin{array}{c}\text { DIME } \\
\text { NSIO } \\
\mathbf{N} \\
\text { INDE } \\
\mathbf{X}\end{array}$ & $\begin{array}{c}\text { HEALT } \\
\text { H } \\
\text { INDEX }\end{array}$ \\
\hline 1 & NALHATI-I & 0.024 & 0.14 & 0.312 & 0.05 & 0.029 & 0.04 & 0.168 & 0.08 & 0.08 \\
\hline 2 & NALHATI-II & 0.028 & 0.24 & 0.288 & 0.03 & 0.019 & $\mathbf{0}$ & 0.167 & 0.06 & 0.08 \\
\hline 3 & MURARAI-I & 0.019 & $\mathbf{0}$ & 0.492 & 0.14 & 0.052 & 0.15 & 0.175 & 0.18 & 0.12 \\
\hline 4 & MURARAI-II & 0.028 & 0.24 & 0.242 & 0.01 & 0.034 & 0.07 & 0.163 & $\mathbf{0}$ & 0.08 \\
\hline 5 & $\begin{array}{c}\text { MAYURESHW } \\
\text { AR-I }\end{array}$ & 0.021 & 0.05 & 0.222 & 0.002 & 0.029 & 0.04 & 0.165 & 0.03 & 0.03 \\
\hline 6 & $\begin{array}{c}\text { MAYURESHW } \\
\text { AR-II }\end{array}$ & 0.035 & 0.43 & 0.46 & 0.12 & 0.027 & 0.04 & 0.177 & 0.21 & 0.2 \\
\hline 7 & $\begin{array}{c}\text { RAMPURHAT- } \\
\text { I } \\
\end{array}$ & 0.044 & 0.68 & 2.192 & 0.97 & 0.245 & 1 & 0.17 & 0.11 & 0.69 \\
\hline 8 & $\begin{array}{c}\text { RAMPURHAT- } \\
\text { II }\end{array}$ & 0.025 & 0.16 & 0.328 & 0.05 & 0.044 & 0.11 & 0.176 & 0.2 & 0.13 \\
\hline 9 & MD. BAZAR & 0.043 & 0.65 & 0.459 & 0.12 & 0.05 & 0.14 & 0.179 & 0.24 & 0.29 \\
\hline 10 & SAINTHIA & 0.034 & 0.41 & 0.268 & 0.02 & 0.028 & 0.04 & 0.188 & 0.38 & 0.21 \\
\hline 11 & DUBRAJPUR & 0.038 & 0.51 & 2.251 & 1 & 0.057 & 0.17 & 0.189 & 0.39 & 0.52 \\
\hline 12 & RAJNAGAR & 0.043 & 0.65 & 0.445 & 0.11 & 0.043 & 0.11 & 0.229 & 1 & 0.47 \\
\hline 13 & SURI-I & 0.051 & 0.86 & 0.746 & 0.26 & 0.041 & 0.1 & 0.166 & 0.05 & 0.32 \\
\hline 14 & SURI-II & 0.039 & 0.54 & 0.403 & 0.09 & 0.039 & 0.09 & 0.182 & 0.29 & 0.25 \\
\hline 15 & $\begin{array}{l}\text { KHOYRASOL } \\
\text { E } \\
\end{array}$ & 0.03 & 0.3 & 0.274 & 0.03 & 0.044 & 0.11 & 0.178 & 0.23 & 0.17 \\
\hline 16 & $\begin{array}{c}\text { BOLPUR- } \\
\text { SRINIKETAN }\end{array}$ & 0.056 & 1 & 1.522 & 0.64 & 0.174 & 0.69 & 0.168 & 0.08 & 0.6 \\
\hline 17 & LABPUR & 0.034 & 0.41 & 0.362 & 0.07 & 0.062 & 0.19 & 0.175 & 0.18 & 0.21 \\
\hline 18 & NANNOR & 0.026 & 0.19 & 0.217 & 0 & 0.036 & 0.08 & 0.175 & 0.18 & 0.11 \\
\hline 19 & ILLAMBAZAR & 0.028 & 0.24 & 0.351 & 0.07 & 0.041 & 0.1 & 0.165 & 0.03 & 0.11 \\
\hline
\end{tabular}

Source: Calculated by authors.

Sub centers-population ratio includes both the number of family welfare centers and the sub centers per thousand of population. This is the most peripheral and first contact point between the primary health care system and the community. These indicates the basic structure of rural health care and increasing number of such centers always promotes better awareness and primary first-aid treatment to the local inhabitants. Dimension Index of this parameter stated the same story. Performance of Rajnagar block regarding this parameter stands highest. Other than the Rajnagar block the situation is not up to the mark. Couple of blocks namely, Dubrajpur (0.39) and Sainthia (0.38) has somehow managed to get the second and third place in this section of health care but still they are far from the level of satisfaction. More than that, very interestingly blocks like Bolpur-Santiniketan, Rampurhat-I which has a better performance regarding the rest of the parameters are not even in the list of top five relating to this parameter (Table-I).

\section{Analysis of Health Index:}

Health Index is nothing but the compaction of the previously mentioned health related parameters for analyzing the spatial disparity of the health care system in Birbhum district. According to the result of Health Index, blocks of Birbhum district can be subdivided into three categories such as:

1. Comparatively more developed blocks (Health Index value $=$ above 0.6 ):

This includes only Rampurhat-I (0.69) and Bolpur-Santiniketan (0.60) blocks which has a better performance regarding all the parameters except the last one.

2. Comparatively developed blocks (Health Index $=0.3-0.6$ ):

Dubrajpur (0.52), Rajnagar (0.47) and Suri-I (0.32) constitute this category. They are not as good as Rampurhat-

I and Bolpur-Santiniketan but still manage to retain their positions very close to the satisfaction level.

3. Comparatively less developed blocks (Health Index = less than 0.3):

This group includes rest of the blocks of Birbhum whose performance really needs some careful attention.

So the above categorization clearly suggests remarkable inequality in the development of health care system in Birbhum. But what are the responsible factors behind such disparity? The most important one is the influence of urbanization process. Four among the top five blocks attaining better health care system in Birbhum district keep in touch with the municipal facilities (Table-II). So, clearly impact of urbanization makes a huge difference in the access of health care facility. Urbanization always attracts better infrastructural facility for the economic as well as social development process and health system is not an exception in that case. 
Status Of Rural Health Care And The Hidden Disparity: A Study Of Birbhum District, West Bengal, TABLE-2: URBANISATION AND HEALTH CARE FACILITY.

\begin{tabular}{|l|l|l|}
\hline $\begin{array}{l}\text { TOP FIVE BLOCKS REGARDING } \\
\text { HEALTH CARE SYSTEM IN }\end{array}$ & MUOCKSIPALITIES WITHIN ITS & \\
BIRBHUM DISTRICT & JURISDICTION & \\
\hline Rampurhat-I & Rampurhat-I & Rampurhat \\
\hline Bolpur-Santiniketan & Bolpur-Santiniketan & Bolpur \\
\hline Dubrajpur & Dubrajpur & Dubrajpur \\
\hline Rajnagar & Sainthia & Sainthia \\
\hline Suri-I & Suri-I & Suri \\
\hline
\end{tabular}

Source: District Statistical Handbook, Birbhum 2007-2008.

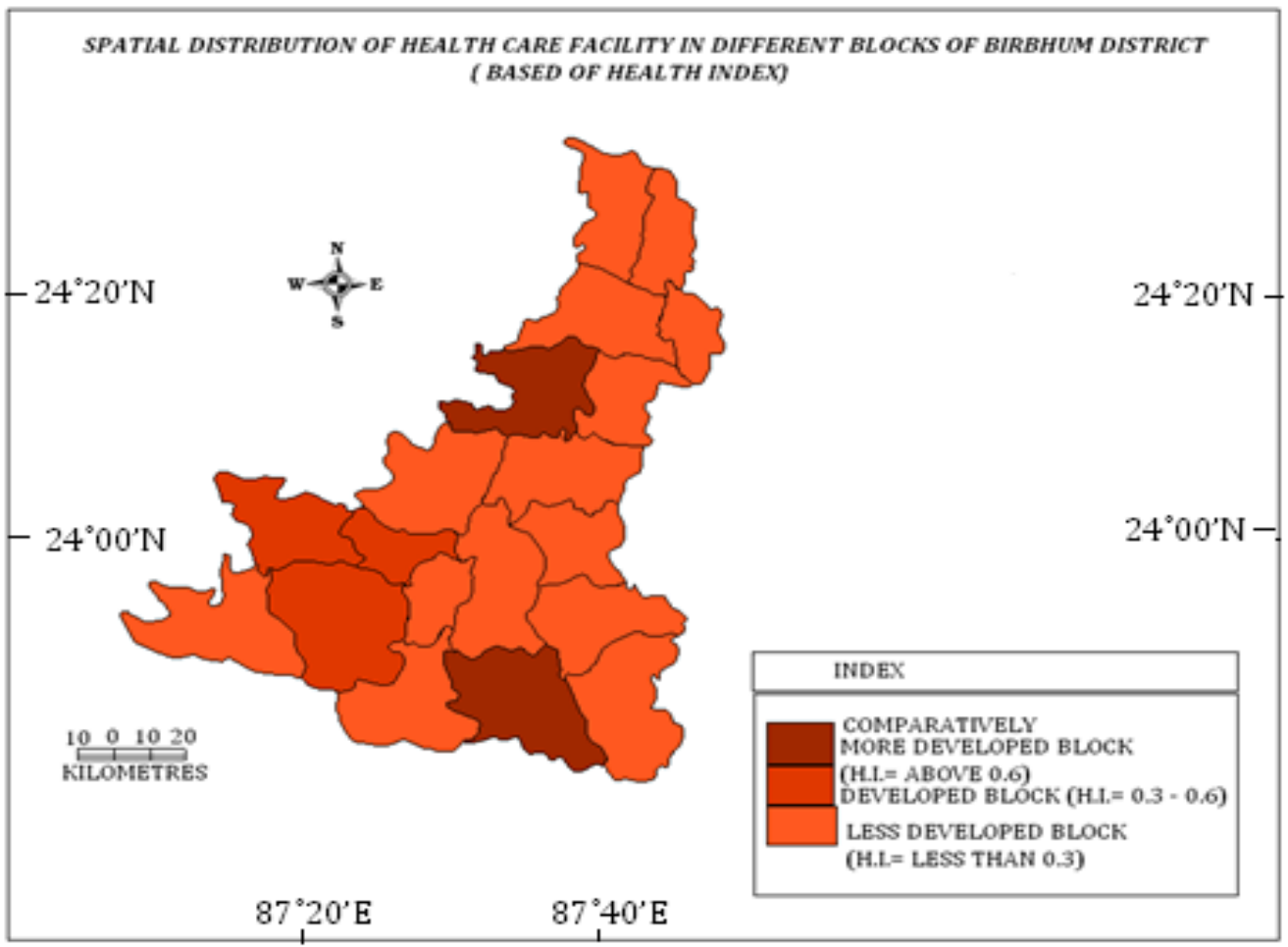

FIGURE-2: SPATIAL VARIATION OF HEALTH CARE FACILITY IN BIRBHUM DISTRICT, WEST BENGAL.

Temporal variation in health care facility in Birbhum:

Considering the temporal growth of the previously mentioned health related parameters exhibits some interesting findings. During the period of 2004-2008, all the indicators show a patterned development. The development process has undergone through three stages. These are:

A. Stagnant stage:

The first couple of year shows a stagnancy in terms of development of health related indicators. Number of medical institutions (excluding Family Welfare Centers and Sub centers), number of hospital doctors, hospital beds and sub centers all experienced a steady state in terms of quantity.

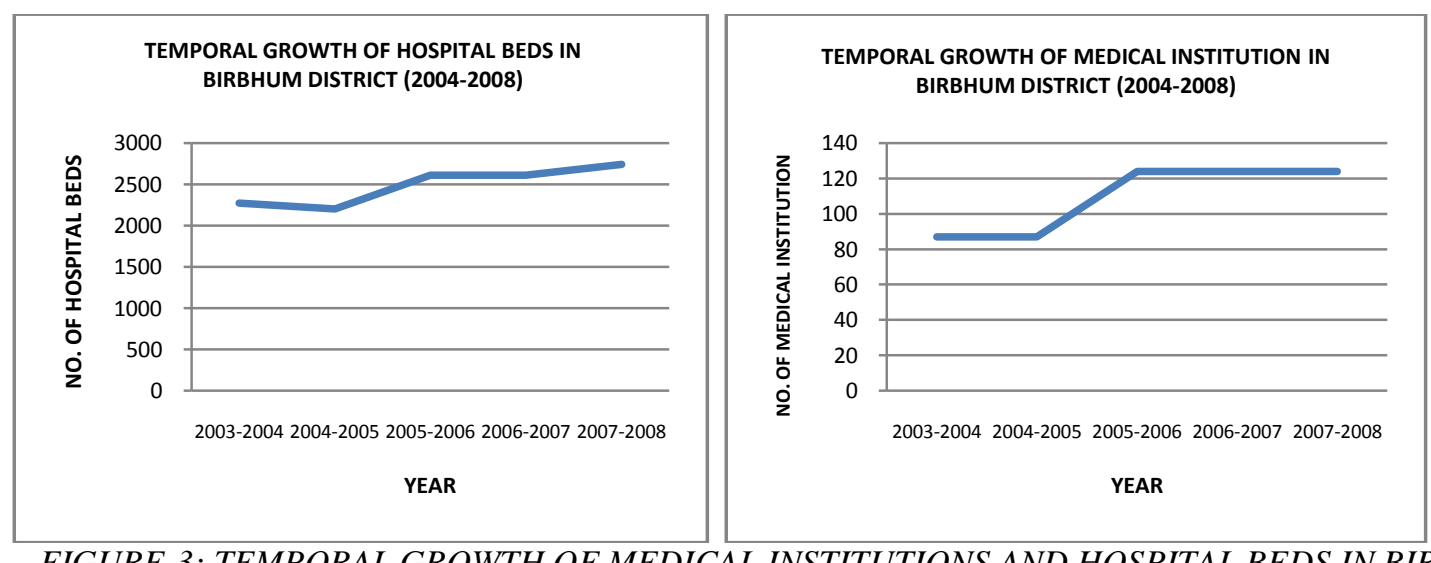

FIGURE-3: TEMPORAL GROWTH OF MEDICAL INSTITUTIONS AND HOSPITAL BEDS IN BIRBHUM. 
Couple of middle year (2005-06 and 2006-07) experienced a sudden growth in terms of medical infrastructure. Number of hospital doctors increases in this time to keep the pace with the increasing number of both medical institution and hospital bed facilities. But the number of Family Welfare Centers and Sub centers shows a mark decrease because of their transformation into Primary Health Centers and Rural health Centers.

\section{C.Steady development stage:}

The rest of the time period shows a steady state condition of health care facility in Birbhum district, although qualitative upgradation of the existing health related infrastructure continues. But very surprisingly the number of hospital doctors decreases this time very rapidly due to some unknown reasons.

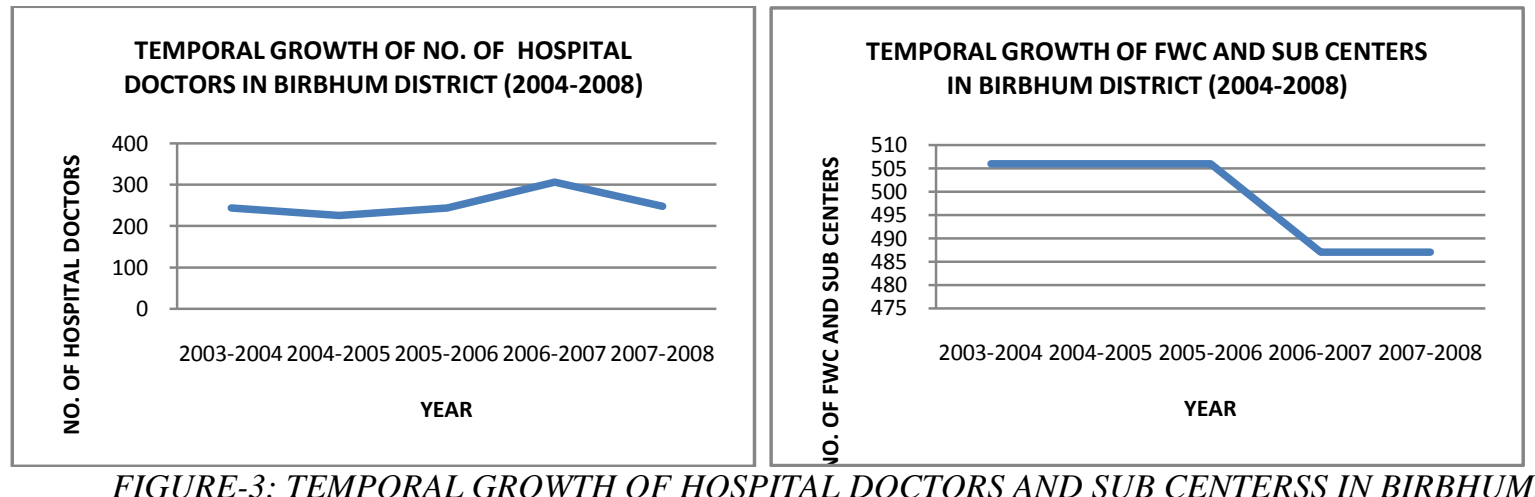

\section{Recommendations:}

Development of proper planning strategies and perfect implementation are the final answer to overcome the discrepancies of health care system in Birbhum district. Better implementation of various governmental plans such as National Rural Health Mission Scheme, Scheme of Universal Health Coverage for the infrastructural attainment is required. But other than governmental plans and policies, public-private joined venture in this regard always become an effective step. More than that, better health awareness among common people and socio-economic reforms are required not only for the development of health care system but also for the all-round development of the society.

\section{Conclusion:}

Betterment of society completely depends on the degree of health care, education and proper nourishment provided to the people of that community. All of these three development indicators are inter twined with each other, so betterment or degradation of any one affects the entire system. Thus an overall socioeconomic reform sounds louder to treat such type of social diseases. More than that, greater pace of urbanization process along with some positive as well as encouraging measures are the immediate steps for better and balanced health care system in Birbhum district.

11] District Statistical Handbook of Birbhum, 2007-2008.

[2] Finley, Jocelyn. (2007), The Role of Health in Economic Development. PGDA Working paper no. - 21, March 27, 2007. Website: http. // www.hsph.harvard.edu/pgda/working.htm.

[3] Canning David. (2010), Progress in Health around the World, Human Development Research Paper, 2010/43, October 2010, UNDP.

[4] Bloom e David \& Canning David. (2000), Health and Wealth of Nations, Science compass, Policy Forum, Vol-287, February 18, 2000. Website: www.sciencemag.org.

[5] Country Cooperation Strategy at a glance: India, a WHO publication. 